\author{
М.Ю. Барбашин
}

\title{
ИНСТИТУТЫ ВЫСШЕГО ОБРАЗОВАНИЯ И СОЦИАЛЬНЫЕ ДИЛЕММЫ (КОМПАРАТИВНЫЙ АНАЛИЗ РОССИЙСКОЙ И АМЕРИКАНСКОЙ ОБРАЗОВАТЕЛЬНЫХ СИСТЕМ)
}

Аннотация. В статье анализируются институичональные процессы в системе высшего образования в России и в Соединенных Штатах. Подчеркивается, что высшее образование необходимо для гражданского развития, поскольку демократическому обществу требуются образованные граждане для участия в решении актуальных государственных задач. Поскольку одной из заявленных иелей институииональных реборм системы университетов является переход кобразованию инноваиионного уровня, который позволил бы обеспечить приемлемый уровень подготовки специалистов в сравнении с ведущими университетами (в первую очередь, американскими), необходимо рассмотреть в рамках компаративного анализа институииональные процессы, учет которых обеспечит позитивные изменения. Применяя положения компаративного анализа и неоинституиионализма, автор рассматривает ключевые образовательные институты, имплементация которых в российскую образовательную среду с учетом ее национальной специфики облегчила бы переход к инновационному образованию, повышению качества профессиональной подготовки специалистов и достижение российскими вузами мирового уровня.

Ключевые слова: образование, неоинституицонализм, институты, университет, трансформации, компаративньй анализ, сочиальные дилеммы, российкое общество, реборма образования, академическое сообщество.

И нститут высшего образования представляет собой не только канал социальной мобильности, но и нормативный образец социальных стремлений людей. Развитие гражданского общества невозможно в необразованной социальной среде.

Высшее образование необходимо для гражданского развития, поскольку демократическому обществу требуются образованные граждане для участия в решении актуальных государственных задач. Однако российский университет так и не смог (за некоторыми исключениями в основном в Москве и Санкт-Петербурге) стать независимым аналитическим и творческим центром, готовым к восприятию новых идей, социально ответственным перед обществом и государством, превратившись в источник институциональной “двусмысленности", неустойчивых дилемм и социального исключения больших групп необеспеченной молодежи. Логичным и вполне ожидаемым следствием является рост численности дезориентированных социальных аутсайдеров и “внутренних мигрантов", которые отчуждаются от общественной жизни.
Говоря словами С. Хантингтона ${ }^{1}$, уважение к ценностям образования находится на низком уровне, студенты рассчитывают, что их жизненный успех будет определяться статусом или неформальными связями родителей. Институциональные провалы системы высшего образования особенно значимы в условиях возросшего в последние годы бюджетного финансирования в рамках национальных программ. Поскольку подавляющая часть студентов принадлежит к средним и высшим слоям, в системе высшего образования России, как и в странах третьего мира, происходит редистрибуция экономических ресурсов в пользу обеспеченных слоев. В результате богатые группы становятся богаче, а социальные аутсайдеры - беднее.

Поскольку одной из заявленных целей институциональных реформ системы университетов является переход к образованию инновационного уровня, который позволил бы обеспечить приемлемый уровень подготовки специалистов в сравнении с ведущими

\footnotetext{
1 Хантингтон С. Политический порядок в меняющихся обществах. М., 2004. С. 210.
} 


\section{Педагогика и просвещение 2(10) • 2013}

университетами (в первую очередь, американскими), необходимо рассмотреть в рамках компаративного анализа институциональные процессы, учет которых обеспечит позитивные изменения.

Высшее образование невозможно рассматривать в отрыве от других социальных институтов, которые задают параметры институциональных изменений. В США большую роль в развитии высшего образования сыграла традиционно развитая у протестантов приверженность к чтению Библии (в т.ч. к грамотности и счету), религиозные убеждения которых исходят из необходимости упорядочивания природного и общественного хаоса посредством обученного сообщества ${ }^{2}$.

Фактически история университетов в США начинается со второй половины XIX в. Первый исследовательский университет "германского" образца появился в Балтиморе в 1872 г. Рост общественного интереса к высшему образованию был вызван технологической революцией, которая проявлялась в строительстве железных дорог и телеграфных линий. Смена демографического паттерна от традиционного к индустриальному привела к росту рождаемости, вызванному введением новых санитарных норм и появлением учреждений здравоохранения в городах. Количество молодых людей, получающих образование, резко возросло.

К началу 1890-х гг. колледж стал новым институтом социальной мобильности ${ }^{3}$. Правящие классы, сколотившие капиталы в период Гражданской войны (в разгар которой в 1863 г. была создана Национальная академия наук) и послевоенной реконструкции самыми различными способами, стали рассматривать высшее образование как символическую ценность, свидетельство высокого престижа и статуса. В этот период появились новые и существующие до сих пор институты экономической поддержки университетов: профессиональные ассоциации, суденческие братства, религиозные сообщества, организации выпукников, частные клубы, общежития, спортивные команды и пр. Группы влиятельных и успешных выпускников использовались университетами также с целью освобождения Alma mater от клерикального или политического контроля ${ }^{4}$.

\footnotetext{
2 Berman H.J. Law and Revolution: The Formation of the Western Legal Tradition. Massachusetts and London, Cambridge: Harvard University Press, 1983. P. 25-26.

3 Charles F. Thawing: The American College in American Life. New York: New York University Press, 1997. P. 273.

${ }^{4}$ Morison S.E. Three Centuries of Harvard 1636-1936. Cambridge: Cambridge University Press, 1936. P. 309.
}

В конце XIX в. появились национальные рейтинговые системы. Поскольку финансирование университета зависит от его позиции в образовательной и/или научной рейтинговой системе, произошла постепенная профессионализация университетского менеджемента и сферы администрирования трудоустройства выпускников.

Процессы трансформации немногочисленных элитарных университетов, перенесенных из Великобритании на почву американского континента в XVII-XVIII вв., в институты массового и относительно недорогого образования в XIX в. были сложными и длительными. По мнению современных историков, даже такие частные образовательные комплексы как Гарвард, Йельск или Колумбийский университет не смогли бы пережить период институционализации без государственной финансовой поддержки 5 . В конце XIX в. (в маркоисторическом отношении это период структурирования национального государства и первых американских колониальных войн с Мексикой и Испанией) основными ее формами были лотереи и дарование свободной земли Поэтому большинство университетских кампусов расположены в деловых и административных городских центрах, а коммерческое использование принадлежащей университетам недвижимости и земли является одним из основных источников внеобразовательных доходов.

Однако финансовой поддержки со стороны штатов и федеральных властей обычно не хватало, и потому университеты часто прибегали к таким “экзотическим" решениям как поиски "профессоров с независимыми источниками доходов" ${ }^{\prime \prime},-$ своеобразной торговле профессорскими званиями. Отголоски этого явления остались в институте совместительства (Adjunct Professor) как противоположности пожизненной профессуры (tenure), поддерживаемой нормативными университетскими структурами, когда за относительно низкую заработную плату и без социальных гарантий администрация университета набирает экспертов-практиков (в области права, медицины и т.д.) для преподавания. Предполагается, что эксперты с другим основным доходом (заработной платой или пенсией), будут передавать студентам только практические навыки и умения -

\footnotetext{
${ }^{5}$ Blackmar F.W. The History of Federal and State Aid to Higher Education in the United States (Washington: Free Press), 1890.

${ }^{6}$ Kingsley W.L. ed. Yale College: A Sketch of Its History (New York: Basic Books), 1979. P. 77-92.

7 Woodburn J.A. History of Indiana University: 1880-1902. Bloomington: Indiana University Press, 1940. P. 244-245.
} 


\section{Образование}

без проверки дипломов и курсовых работ. Однако фактически на дискриминационных условиях работают многие "чистые" профессора, вынужденные подрабатывать временно-контрактными совместителями сразу в нескольких университетах. Качество американского высшего образования снижается, не в последнюю очередь из-за роста численности "неошабашников" и "академических номадов".

Государственная поддержка по-прежнему необходима системе высшего образования. Современный бюджет частного Гарварда на четверть формируется государством, при этом правительство финансирует более $70 \%$ фундаментальных исследований 9 .

И хотя консерваторы подчеркивают, что механическое увеличение образовательных кредитов, грантов и субсидий не сможет исправить социальные дефекты, в т.ч. низкий уровень успеваемости расовых и этнических меньшинств, эти суммы количественно постоянно возрастают, поскольку увеличивается скорость технологических изменений, которые должна изучать наука, и поскольку ни одно частное или общественное агентство не может финансировать половину молодежи США, получающей высшее образование ${ }^{10}$.

Структурные сдвиги в финансировании образования вызываются политическими причинами: интерес к инженерным и техническим наукам возрос после запуска в Советском Союзе искусственного спутника, когда стало очевидным, что запад проигрывает космическую гонку, а интерес к социальным наукам пробуждался необходимостью получать достоверные политические прогнозы со стороны советологии. Для Соединенных Штатов характерна более активная (чем в России) экспертная вовлеченность ученых в обсуждение актуальных социально-экономических проблем.

Высокая зависимось от государственного финансирования и частных доноров ускоряет реакцию американских университетов на внешние вызовы. В 2000-х г. в социально-гуманитарной сфере государственные финансовые потоки были перенаправлены востоковедам, специалистам по Ближнему Востоку, Афганистану или Центральной Азии. К примеру, в 2005 году Чикагский университет открыл “Центр по

\footnotetext{
8 Wee E.L. Professor of Desperation // Washington Post, Sunday. 2002. (July 21).

9 Harvard and the Federal Government: A Report to the Facilities and Governing, Boards of Harvard University. Cambridge: Cambridge University Press, 1961. P. 1-4.

${ }^{10}$ Kidd C.V. New Government - University Relationships in Research // Higher Education, (XVI). 1960. № 3-6.
}

изучению Узбекистана". После терактов 11 сентября 2001 г. во многих вузах появились специализации по изучению арабского языка, фарси, а также других восточных языков.

Важным институциональным процессом является корпоративизация (сопровождаемая капитализацией высшего образования в США. Все большее число молодежи учатся в корпоративных университетах, которых более 1200 (самые известные из них - университеты Моторолы, Майкрософта, Диснея и Макдональдса). Это не просто "социальная нагрузка" корпораций, как указывают В.М. Коэн и Д.А. Левинталь ${ }^{11}$, компании занимаются инвестициями в науку и высшее образование не для того, чтобы делать открытия, а чтобы узнавать об открытиях других. Поскольку даже крупная корпорация проводит лишь небольшое количество специализированных исследований, компании нанимают ученых, чтобы быть в курсе научной литературы и исследований, ведущихся в других странах и организациях.

Первая в мире венчурная инвестиционная компания была создана в США в 1946 году, причем цель ее состояла в коммерциализации создаваемых в университетах технологий и патентов. Успех американских венчурных компаний привел к ускорению перевода научных тезисов в патенты. Сейчас средний промежуток составляет четыре года ${ }^{12}$.

Стремясь получить корпоративное финансирование, многие вузы заключают соглашения о спонсорстве с такими компаниями, как "Reebok", "Sony" и пр.) и/или создают новые бренды и торговые марки, выпуская, в частности, одежду с своими логотипами. Как частные, так и государственные университеты должны конкурировать в сфере донорства и фандрайзинга за получение бюджетных, корпоративных и грантовых средств, частных пожертвований, помощи и субсидий. Грантовый источник финансирования становится более весомым и в российских вузах.

Однако американский грант отличается от схожего финансового института в России. В США грант - это денежные или иные пожертвования со стороны корпораций, фирм, муниципальных или религиозных сообществ или частных лиц, которые используются на научные, академические и образовательные нужды и вычитаются из налого-

${ }^{11}$ Cohen W.M. and Levinthal D.A. 1989. Innovation and Learning: The Two Faces of R\&D // Economic Journal. 1989. № 99. P. 569-596.

${ }_{12}$ Narin F. and Olivastro D. 1992. Status Report: Linkage Between Technology and Science // Research Policy. 1992. № 21. P. 237-249. 


\section{Педагогика и просвещение 2(10) • 2013}

облагаемой базы. Относительно небольшое место в общем грантовом "пуле" занимают национальные фонды, институты и неправительственные организации.

Обычно американский профессор выигрывает не более пяти - шести грантов в ходе профессиональной деятельности: как правило, на завершение подготовки диссертации, издание монографии или проведение полевых исследований для сбора эмпирического материала, на открытие лаборатории или специализированного исследовательского центра (средства выделяются обычно на первые два три бюджетных года). Высокая заработная плата в системе высшего образования позволяет преподавателям рассматривать гранты как побочный источник дохода. В России же средний годовой грант (со стороны, например, РФФИ или РГНФ) вполне сопоставим с небольшой годовой заработной платой, и гранты больше выполняют социальные функции компенсации ученым и преподавателям низких бюджетных доходов.

Системы грантовых фондов и эндаументов в США уже длительное время (в отличие от России, в которой университетские эндаументы появились в 2000-е г.) встроены в систему образовательных отношений. Первый образовательный “Фонд Вильяма Уайта" появился в 1803 г. $^{13}$. Наиболее известные в настоящее время фонды появились во второй половине XIX в. (“Фонд образования Пибади” в 1867 г. и “Институт Карнеги” в 1896 г.) $)^{14}$ — в начале XX века во многом как PR - проекты американской элиты по улучшению социального имиджа: в 1903 г. создан “Фонд Общего Образования Рокфеллера" с объемом средств в 46 млн. долларов, “Фонд Образования Рокфеллера" в 1913 г. с ресурсами 154 млн. долларов, “Фонд Карнеги” в 1906 г. с грантовым пулом в 31 млн. долларов и Корпорация Карнеги, бюджет которой составлял 151 млн. долларов.

В конкурентной образовательной среде функционирует институты, которые неоинституционалисты называют “правилами входа"15 и которые регулируют доступ к академическому пространству. В частности, институт "академической мобильности" заставляет американские университеты

\footnotetext{
${ }^{13}$ Keppel F.P. The Foundation: It's Place in American Life. New York: Basic Books, 1930. P. 17.

${ }^{14}$ Hollis E.V. Philanthropic Foundations and Higher Education. New York: Basic Books, 1938.

15 Crawford S.E.S. and Ostrom E. A Grammar of Institutions // Understanding Institutional Diversity ed. by E. Ostrom. Princeton, NJ: Princeton University Press, 2005. P. 137-174.
}

соперничать между собой за преподавателей, а преподавателей - конкурировать за небольшое количество хорошо оплачиваемых профессорских и научных должностей.

В академическом сообществе (особенно в сфере социальных, гуманитарных и политических наук) существуют достаточно жесткие институциональные ожидания: предполагается, что получив степень магистра в одном учебном заведении, студент для продолжения образования на докторском уровне перейдет в другой университет, начнет преподавательскую карьеру - в третьем, а звание профессора получит в четвертом учреждении. Социальные экзептации модального карьерного пути приводят к тому, что средний преподаватель или ученый в академической деятельности меняет пять-шесть работ.

Неэффективная социокультурная трансмиссия приводит к девальвации в российском социуме другого важного западного института - рекомендательных писем. Их ресурсным основанием является важность символического капитала, необходимого для профессионального развития и академической мобильности. Социальный капитал является одинаково важным как для рекомендующего, так и для рекомендуемого. Как и прочие атрибуты западной научной институциональной системы, рекомендации были перенесены в российскую практику в начале 1990-х. Однако функции подобных писем в национальных конкурсах и грантовых программах инперсистентны и девальвированы, поскольку отправляя такое письмо (или просто подписывая предоставляемый готовый вариант), российский ученый (в отличие от своих американских коллег) фактически не рискует ни репутацией, ни символическим капиталом, ни, тем более, материальными благами.

Поддержание высокого уровня обраовательной конкуренции напрямую зависит от притока транстерриториальных академических номадов из стран с низким уровнем развития как претендентов на профессорские должности в США. Социально-психологический образ “человека академического" 16 сформировался в контексте институциональных тенденций к удлинению срока обучения в американской аспирантуре: стремясь "улучшить" резюме, аспиранты обычно год или два проводят полевые исследования в регионах специализации, затем год или два уходит на теоретические исследования, много времени тратится на подготовку монографии,

16 Bourdieu P. Homo Academicus. Cambridge: Polity Press, 1984. 


\section{Образование}

с чем связаны более строгие, чем в России, издательские требования (фактическая невозможность издать монографию "за свой счет" и в короткие сроки, многоступенчатый процесс рецензирования и обсуждения рукописи и т. п.).

Среднее количество времени, необходимое для защиты диссертации, постепенно повышается. В 2003 г. защита Ph.D занимала в университетах США в среднем 7,5 лет, а средний возраст получения степени учеными составил 33,4 года. Но в конкретных направлениях ситуация отличается от средних показателей:

31,8 лет - в естествознании,

34,6 лет - в гуманитарных науках,

43,5 лет - в образовании,

37,5 лет - в инженерных науках ${ }^{17}$.

Распространенным мифом в российских академических кругах является представления об особой образовательной мотивации американской молодежи, необходимых для получения хороших профессиональных навыков. В реальности особой самодисциплины не существует. Даже в элитных университетах фактически треть студентов экономических курсов не посещает занятий ${ }^{18}$. Основным институциональным различием по сравнению с учебной несамостоятельностью российских студентов является то, что американские студенты сами выбирают большинство предметов в зависимости от карьерных планов и/или договоренностей с потенциальными работодателями.

Более свободный выбор учебных программ у американских студентов связан не только с историческими традициями университетской автономии и общей флексибильностью университетов к рынку труда. Структура социальных ожиданий в американском обществе эластичнее и не носит жесткого позиционного характера, как в России.

Причины горизонтальной структуры социальных ожиданий заключаются в особенностях американской истории. Как указывала М. Мид ${ }^{19}$, неоднородность этносоциального пространства послужила причиной отсутствия общенациональной элиты в европейском понимании. Человек, занимающий высокое положение в своем сообществе, необяза-

\footnotetext{
17 Reis R.M. Tomorrow's Professor. Preparing for Academic Careers in Science and Engineering. New York: Basic Books, 1997.

18 Romer D. Do students go to class? Should They? // Journal of Economic Perspectives. 1993. № 7(3). Summer. P. 167-174.

${ }^{19}$ Mead M. Ethnicity in America // De Vos, George A., and L. Romanucci-Ross, eds. Ethnic Identity: Cultural Continuities and Change. Palo Alto: Mayfield, 1975. P. 310-312.
}

тельно займет такое же положение в другом штате. Но верно и обратное. Неудача в продвижение в одном месте не означала, что негативный результат ждет человека повсюду. Тем самым существовали высокие возможности социально-географической мобильности, и если карьера не удавалась в одном месте, американцы (включая преподавателей) могли легко переехать.

С неоинституциональной точки зрения академический номадизм приводит к реструктурированию образовательных сообществ ${ }^{20}$. Если академические сети являются плотными, то для трансмиссии информации за ее пределы требуется больше времени и ресурсов ${ }^{21}$. И наоборот, чем слабее межличностное сцепление и проще перейти из одного образовательного сообщества в другое, тем быстрее происходит кросс-территориальный перенос идей и технологий и конвергенция наработок различных школ в новые парадигмы и теории ${ }^{22}$. Тем проще установить "мосты" между разными академическими группами. Формируются обширные профессиональные сети, которые помогают карьерному продвижению, формируя чувство “сообщества”. Это облегчает академическую мобильность, которая не только предоставляет ученому инструменты для решения его социальных и/или экономических проблем, но и сохраняет стабильность системы высшего образования. Такие "клапаны" снижают давление неудовлетворенных групп интеллигенции и не дают социальному напряжению перерасти во взрывные формы протеста.

В США высшее образование не носит рестриктивного характера: студент поступает на факультет физики, может проучиться там три-четыре года, затем пару лет поработать в "Корпусе мира" (своеобразная вариация дауншифтинга) и заново начать обучение на медицинском факультете. Существующая система поощряет образовательные эксперименты, что на институциональном уровне выражается в большом количестве программ свободного и дополнительного обучения.

Российским студентам предлагается бинарная модель социальной карьеры: в бизнес-структурах

${ }^{20}$ Granovetter M.S. The Strength of Weak Ties: A Network Theory Revisited // Sociological Theory. 1983. Vol. (1).

${ }^{21}$ Friedkin N.E. A Test of the Structural Features of Granovetter's Strength of Weak Ties' Theory // Social Networks (2). 1980. P. 411-422.

${ }^{22}$ Collins R. The European Sociological Tradition and 21st Century World Sociology // Abu-Lughod J.L. by ed. Sociology for the Twenty-first Century: Continuities and Cutting Edges. Chicago: Chicago University Press, 1999. P. 26-42. 


\section{Педагогика и просвещение 2(10) • 2013}

или в государственном управлении. Иногда карьера может быть академической или преподавательской, которая, в конечном счете, переходит либо в первый вариант, либо во второй. Дополнительные каналы социальной мобильности немногочисленны и узявимы: в России практически отсутствуют международные и неправительственные организации, агенства, фонды и т.п.

В американском социуме получение хорошей работы в большей степени зависит от индивидуальных достижений студента, а в России лучшим способом социальной карьеры остается "удачный выбор собственных родителей”. Отсутствие очевидной меритократической связи между результатами студента и его будущим профессиональным доходом (даже "красный” диплом не гарантирует ни жизненного успеха, ни хотя бы высоко оплачиваемой), нацеливает систему высшего образования на таргетированную девальвацию качества обучения.

Еще одним институциональным дефектом является усиление институтов внешнего контроля, при слабости и недостаточном внимании к самомотивации. Минимизация учебных усилий российских студентов ${ }^{23}$, наряду с распространением фальшивых ЕГЭ, “коммерческих" диссертаций и пр., являются результатом демеритократизации российского социума и общей институциональной деградации социального пространства ${ }^{24}$. В россий- ских институциональных условиях жизненный успех лишь опосредованным образом связан с качеством получаемого образования. Действуя в рамках оптимума Парето и стремясь минимизировать усилия для достижения максимального результата, студенты, как рационально действующие социальные агенты, часто переключают энергию на поиски дополнительной оплачиваемой занятости, участие в деятельности неформальных молодежных группировок и т.п.

Рассмотренные институциональные особенности образовательной системы не являются детерминированными. Не обязательно заимствовать все американские институты. Однако если выборочно "вытаскивать" из западных систем высшего образования один или два элемента (наподобие трехуровневой системы бакалавр-специалист-магистр) и использовать их в качестве основы для остальных институциональных преобразований, результат неизбежно окажется негативным.

Существующее положение дел не может считаться удовлетворительным. Система высшего образования должна быть открыта внешнему влиянию, чтобы не напоминать собой поведение одного американского фермера, который удивил чиновника графства тем, что не захотел узнавать новую информацию, как лучше возделывать земельные угодья. Фермер объяснил это так: “Я уже знаю, как делать лучше, чем я делаю"25.

\section{Список литературы:}

1. Асланов Я.А., Барбашин М.Ю., Барков Ф.А., Крамарова Е.Н. (рук. авт. колл.), Янакова Е.В. Комплексный портрет студентов Южного федерального университета. Ростов-н/Д: МАРТ, 2013.

2. Барбашин М.Ю. Процедурная демократия и социальная структура: неоинституциональный анализ // Политика и общество. 2010. № 11. С. 16-26.

3. Попов Е.А. Социологический анализ роли управленческой структуры вуза в обеспечении качества высшего образования // Политика и общество. 2012. № 2. С. 110-117.

4. Труфанова Е.О., Яновская О.Р. Институт образования в обществе знаний // Педагогика и просвещение. 2012. № 3. С. 30-43.

5. Хантингтон С. Политический порядок в меняющихся обществах. М., 2004.

6. Щербак Е.Н. Правовые проблемы государственного управления в области высшего образования в России в контексте развития образовательного рынка и глобализации // Политика и общество. 2011. № 12. С. 45-49.

\footnotetext{
${ }^{23}$ Асланов Я.А., Барбашин М.Ю., Барков Ф.А., Крамарова Е.Н. (рук. авт. колл.), Янакова Е.В. Комплексный портрет студентов Южного федерального университета. Ростов-на-Дону: МАРТ, 2013.

${ }^{24}$ Барбашин М.Ю. Процедурная демократия и социальная структура: неоинституциональный анализ // Политика и общество. 2010. № 11. С. 16-26.
}

${ }^{25}$ Walstad W.B., Saunders P. Teaching Undergraduate Economics: A Handbook for Instructors. Irwin/McGraw-Hill, 1998. P. 75. 


\section{Образование}

7. Berman H.J. Law and Revolution: The Formation of the Western Legal Tradition. Massachusetts and London, Cambridge: Harvard University Press, 1983. P. 25-26.

8. Blackmar F.W. The History of Federal and State Aid to Higher Education in the United States (Washington: Free Press), 1890.

9. Bourdieu P. Homo Academicus. Cambridge: Polity Press, 1984.

10. Charles F. Thawing: The American College in American Life. New York: New York University Press, 1997. P. 273.

11. Cohen W.M. and Levinthal D.A. 1989. Innovation and Learning: The Two Faces of R\&D // Economic Journal. 1989. № 99. P. 569-596.

12. Collins R. The European Sociological Tradition and 21st Century World Sociology // Abu-Lughod J.L. by ed. Sociology for the Twenty-first Century: Continuities and Cutting Edges. Chicago: Chicago University Press, 1999. P. 26-42.

13. Crawford S.E.S. and Ostrom E. A Grammar of Institutions // Understanding Institutional Diversity ed. by E. Ostrom. Princeton, NJ: Princeton University Press, 2005. P. 137-174.

14. Friedkin N.E. A Test of the Structural Features of Granovetter's Strength of Weak Ties' Theory // Social Networks (2). 1980. P. 411-422.

15. Granovetter M.S. The Strength of Weak Ties: A Network Theory Revisited // Sociological Theory. 1983. Vol. (1).

16. Harvard and the Federal Government: A Report to the Facilities and Governing, Boards of Harvard University. Cambridge: Cambridge University Press, 1961. P. 1-4.

17. Hollis E.V. Philanthropic Foundations and Higher Education. New York: Basic Books, 1938.

18. Keppel F.P. The Foundation: It's Place in American Life. New York: Basic Books, 1930. P. 17.

19. Kidd C.V. New Government — University Relationships in Research // Higher Education, (XVI). 1960. № 3-6.

20. Kingsley W.L. ed. Yale College: A Sketch of Its History (New York: Basic Books), 1979. P. 77-92.

21. Mead M. Ethnicity in America // De Vos, George A., and L. Romanucci-Ross, eds. Ethnic Identity: Cultural Continuities and Change. Palo Alto: Mayfield, 1975. P. 310-312.

22. Morison S.E. Three Centuries of Harvard 1636-1936. Cambridge: Cambridge University Press, 1936. P. 309.

23. Narin F. and Olivastro D. 1992. Status Report: Linkage Between Technology and Science // Research Policy. 1992. № 21. P. 237-249.

24. Reis R.M. Tomorrow's Professor. Preparing for Academic Careers in Science and Engineering. New York: Basic Books, 1997.

25. Romer D. Do students go to class? Should They? // Journal of Economic Perspectives. 1993. № 7(3). Summer. P. 167-174.

26. Walstad W.B., Saunders P. Teaching Undergraduate Economics: A Handbook for Instructors. Irwin/McGrawHill, 1998. P. 75.

27. Wee E.L. Professor of Desperation // Washington Post, Sunday. 2002. (July 21).

28. Woodburn J.A. History of Indiana University: 1880-1902. Bloomington: Indiana University Press, 1940. P. 244-245.

\section{References (transliteration):}

1. Aslanov Ya.A., Barbashin M.Yu., Barkov F.A., Kramarova E.N. (ruk. avt. koll.), Yanakova E.V. Kompleksnyy portret studentov Yuzhnogo federal'nogo universiteta. Rostov-na-Donu: MART, 2013. $288 \mathrm{~s}$.

2. Barbashin M.Yu. Procedurnaya demokratiya i social'naya struktura: neoinstitucional'nyy analiz // Politika i obschestvo. 2010. № 11. S. 16-26.

3. Popov E.A. Sociologicheskiy analiz roli upravlencheskoy struktury vuza v obespechenii kachestva vysshego obrazovaniya // Politika i obschestvo. 2012. № 2. C. 110-117.

4. Trufanova E.O., Yanovskaya O.R. Institut obrazovaniya v obschestve znaniy // Pedagogika i prosveschenie. 2012. № 3. C. 30-43.

5. Hantington S. Politicheskiy poryadok v menyayuschihsya obschestvah. M., 2004.

6. Scherbak E.N. Pravovye problemy gosudarstvennogo upravleniya $\mathrm{v}$ oblasti vysshego obrazovaniya $\mathrm{v}$ Rossii $\mathrm{v}$ kontekste razvitiya obrazovatel'nogo rynka i globalizacii // Politika i obschestvo. 2011. № 12. C. 45-49.

7. Berman H.J. Law and Revolution: The Formation of the Western Legal Tradition. Massachusetts and London, Cambridge: Harvard University Press, 1983. P. 25-26.

8. Blackmar F.W. The History of Federal and State Aid to Higher Education in the United States (Washington: Free Press), 1890. 


\section{Педагогика и просвещение 2(10) • 2013}

9. Bourdieu P. Homo Academicus. Cambridge: Polity Press, 1984.

10. Charles F. Thawing: The American College in American Life. New York: New York University Press, 1997. P. 273.

11. Cohen W.M. and Levinthal D.A. 1989. Innovation and Learning: The Two Faces of R\&D // Economic Journal. 1989. № 99. P. 569-596.

12. Collins R. The European Sociological Tradition and 21st Century World Sociology // Abu-Lughod J.L. by ed. Sociology for the Twenty-first Century: Continuities and Cutting Edges. Chicago: Chicago University Press, 1999. P. 26-42.

13. Crawford S.E.S. and Ostrom E. A Grammar of Institutions // Understanding Institutional Diversity ed. by E. Ostrom. Princeton, NJ: Princeton University Press, 2005. P. 137-174.

14. Friedkin N.E. A Test of the Structural Features of Granovetter's Strength of Weak Ties' Theory // Social Networks (2). 1980. P. 411-422.

15. Granovetter M.S. The Strength of Weak Ties: A Network Theory Revisited // Sociological Theory. 1983. Vol. (1).

16. Harvard and the Federal Government: A Report to the Facilities and Governing, Boards of Harvard University. Cambridge: Cambridge University Press, 1961. P. 1-4.

17. Hollis E.V. Philanthropic Foundations and Higher Education. New York: Basic Books, 1938.

18. Keppel F.P. The Foundation: It's Place in American Life. New York: Basic Books, 1930. P. 17.

19. Kidd C.V. New Government — University Relationships in Research // Higher Education, (XVI). 1960. № 3-6.

20. Kingsley W.L. ed. Yale College: A Sketch of Its History (New York: Basic Books), 1979. P. 77-92.

21. Mead M. Ethnicity in America // De Vos, George A., and L. Romanucci-Ross, eds. Ethnic Identity: Cultural Continuities and Change. Palo Alto: Mayfield, 1975. P. 310-312.

22. Morison S.E. Three Centuries of Harvard 1636-1936. Cambridge: Cambridge University Press, 1936. P. 309.

23. Narin F. and Olivastro D. 1992. Status Report: Linkage Between Technology and Science // Research Policy. 1992. № 21. P. 237-249.

24. Reis R.M. Tomorrow's Professor. Preparing for Academic Careers in Science and Engineering. New York: Basic Books, 1997.

25. Romer D. Do students go to class? Should They? // Journal of Economic Perspectives. 1993. № 7(3). Summer. P. 167-174.

26. Walstad W.B., Saunders P. Teaching Undergraduate Economics: A Handbook for Instructors. Irwin/McGrawHill, 1998. P. 75.

27. Wee E.L. Professor of Desperation // Washington Post, Sunday. 2002. (July 21).

28. Woodburn J.A. History of Indiana University: 1880-1902. Bloomington: Indiana University Press, 1940. P. 244-245. 